\title{
Simulation of the desorption process of methane adsorbed in a coal rock, taking into account intermolecular sorption interactions in the system "methane-coal"
}

\author{
Alla Prusova ${ }^{1}$, Oleksandr Minieiev², and Svitlana Ryzhova, ${ }^{1, *}$ \\ ${ }^{1}$ Institute of Geotechnical Mechanics named by N. Poljakov of National Academy of Sciences of \\ Ukraine, 49005, Dnipro, Simferopolska Str., 2a, Ukraine \\ ${ }^{2}$ National University of Technology Dnipro Polytechnic, 49005, Dnipro, Dmytra Yavornytskoho \\ Ave., 19, Ukraine
}

\begin{abstract}
Based on the analysis of the stages of the desorption of methane adsorbed in the coal rock, the simulation of this process was based on its consideration as an activation process of diffusion. It was found that the intermolecular sorption interactions in the "methane-coal" system should be described by the Lennard-Jones potential, taking into account the polymeric nature of the molecular structure of coal. Therefore, an analysis of the modern theories of the kinetics of nonequilibrium sorption processes in high-molecular materials was performed. This analysis showed that the complex of the main molecular factors in the system "methane - coal" can be taken into account most correctly using the Pace - Deutiner molecular parameters. The diffusion coefficient in the equation takes into account the activation energy of the diffusion process, intermolecular sorption interactions in the "methane-coal" system, the parameters of the microstructure of coal, the physical properties of methane and the magnitude of its diffusion jump. The analytical calculation of the diffusion equation is carried out. It allows determining the patterns of the desorption process in various geological conditions of mining operations.
\end{abstract}

\section{Introduction}

At present, the development and introduction of highly efficient technologies for the extraction of coal and gas into the industry is connected with the need to account for methane associated with coal by the sorption bond [1-5]. The patterns of its release desorption determine the preparation and development of various types of gas-dynamic manifestations of rock pressure $[6,7]$. However, the calculations of gas recovery of this gas currently mainly use the Langmuir theory, which does not allow to take into account intermolecular sorption interactions in the "methane-coal" system [8], determined by the structural parameters of the molecular structure of coal and the properties of methane. This

\footnotetext{
*Corresponding author: dieslovo.alfavit@gmail.com
} 
is important because these characteristics condition described [9] the activation energy of desorption and diffusion of desorbed methane, and, consequently, the pattern of desorption of methane in the coal array. In this regard, the goal was set: to perform the simulation of desorption of methane adsorbed in a coal rock, taking into account the intermolecular sorption interactions in the "methane-coal" system.

\section{Methods}

It is known [9] that desorption is the separation of sorbate from sorbent and in general is divided into the following stages: violation of sorption equilibrium, causing activation of the desorption process, and diffusion of the desorbing gas, which carries it through the microporous volume into the macroporous or direct removal of gas from environment. The first stage in coal is determined by the characteristic structure of its molecular structure. This structure, as is known $[10,11]$, consists of two or more types of monomeric units of different chemical nature with their chaotic alternation. It belongs to the copolymers, so it can be attributed to high-molecular media [12]. The main parameter of the first stage of the desorption process, which is characterized by the violation of the sorption equilibrium, is the energy that has reached a value sufficient to transfer the sorbed methane from a state of rest to motion - the activation energy of desorption $E_{a}$. This parameter is also fundamental in determining the diffusion coefficient $D$ in the second stage of the description of the methane desorption process. In this case, the intermolecular interactions of adsorbed methane with coal must be taken into account on the basis that this relationship is mainly due to physical sorption [13]. This sorption implies the interaction of phase states by means of the van der Waals forces [14], which are determined by the Lennard-Jones potential [15, $16]$.

Thus, based on the fact that the molecular structure of coal can be attributed to high polymer materials, an analysis of the existing classical theories of the kinetics of nonequilibrium sorption processes in such media was performed. In this case, the models were analyzed, among which there are two approaches. The first is that diffusion is considered as a thermally activated process - molecular models [17-19]. The second is phenomenological theories of free volume, [20, 21]. As a result, the molecular theory described by the Pace - Deuttiner parameters [19] was chosen for simulation, which most fully allow for the polymeric nature of the molecular structure of coal and its structural features, as well as intermolecular interactions of the dispersed type in the "methane - coal" system van der Waals forces.

\section{Results and its discussion}

Based on the steps described in the methodology, the desorption of methane associated with coal by an intermolecular sorption bond is the diffusion of gas in the coal. This process is realized when the methane molecules reach an activation energy of desorption $E_{a}$. In this regard, the change in methane concentration during its desorption in a spherical fragment of coal of radius $R_{0}$ with an initial concentration of $c_{0}$, which is much greater than the concentration of free methane in the coal array [1], can be described by the diffusion equation in spherical coordinates as follows $[22,23]$ :

$$
\frac{\partial c(r, t)}{\partial t}=D\left(\frac{\partial^{2} c(r, t)}{\partial r^{2}}+\frac{2}{r} \frac{\partial c(r, t)}{\partial r}\right),
$$


where $c(r, t)$ is the concentration of methane; $t$ is time; $r$ is the radial coordinate; $D$ is the diffusion coefficient.

The equation of the diffusion coefficient of methane molecules with the physical and molecular properties of the system "methane-coal" in accordance with [19] can be written as:

$$
D_{d}=\left(9.1 \cdot 10^{-4}\right) \frac{\bar{L}^{2}}{\lambda^{2}}\left(\frac{\varepsilon^{*}}{r^{*}}\right)^{5 / 4}\left(\frac{\sqrt{\beta}}{m^{*}}\right)^{1 / 2} \frac{d^{\prime}}{\partial E_{a} / \partial d} \exp \left(-\frac{E_{a}}{R T}\right)
$$

where $\bar{L}$ is the length of the free diffusion jump of the methane molecule; $\varepsilon^{*}$ and $r^{*}$ are the average values of the parameters of the Lennard-Jones potential [16] for elements of the coal structural chain; $\lambda$ is the average distance between the segments; $\beta$ is a constant characterizing the deformation of the valence angle per unit length of a segment with a molecular mass of $m^{*} ; d^{\prime}=d+r^{*}-l$ is the equivalent diameter of the methane molecule; $l$ - distance between structural chains;

$$
\begin{aligned}
& E_{a}=5.23\left(\frac{\beta}{d^{\prime}}\right)^{1 / 4}\left(\frac{2 \varepsilon^{*} r^{*}}{\lambda^{2}}\right)^{3 / 4}\left\{0.077\left[\left(\frac{2 r^{*}}{l}\right)^{11}\left(l-10 d^{\prime}\right)-2 r^{*}\left(\frac{2 r^{*}}{r^{*}+d}\right)^{10}\right]-\right. \\
& \left.-0.580\left[\left(\frac{2 r^{*}}{l}\right)^{5}\left(l-4 d^{\prime}\right)-2 r^{*}\left(\frac{2 r^{*}}{r^{*}+d}\right)^{4}\right]\right\}^{3 / 4}
\end{aligned}
$$

If the concentration of methane in the cracks completely or partially surrounding the fragment is constant and is $c_{R}$, then the initial and boundary conditions in the general case will be:

$$
c(r, 0)=c_{0}, \quad c\left(R_{0}, t\right)=c_{R} .
$$

This one-dimensional task of methane diffusion is solving by the Fourier method [22, 23]. As a result, the solution is obtained in the from:

$$
c(r, t)=\sum_{n=1}^{\infty} \frac{2\left(c_{0}-c_{R}\right) R_{0}}{n \pi r}(-1)^{n+1} \sin \frac{n \pi r}{R_{0}} \exp \left(-\frac{n^{2} \pi^{2} D t}{R_{0}^{2}}\right)+c_{R} .
$$

Thus, equation (5) describes the variation of the concentration of sorbed methane in the coal fragment of radius $R_{0}$, with its initial concentration $c_{0}$, when a constant concentration $c_{R}$ of methane is maintained at the boundary. Then the concentration of desorbed methane $c_{d}(r, t)$ will be equal by the difference between the initial concentration of methane in the coal $c_{0}$ and the concentration during the diffusion of methane $c(r, t)$.

We define the constants entering into equation (5). The concentration of sorbed methane in the undisturbed coal fragments can be estimated from the known distribution of methane forms in coal [10], which for the sorbed gas is about $80-90 \%$ of the total gas content in the reservoir. Therefore, for the case of the residual desorption of methane in the considered fragment of coal, $c_{0}$ can be determined from the relation:

$$
c_{0}=\frac{c_{R}}{0.2}-c_{R}
$$


The pressure of methane at the boundary of the undisturbed coal fragments with the filtration space of the coal rock, taking into account the Mendeleev-Clapeyron law [14], can be considered equal:

$$
P_{g}=k \gamma H=\frac{N_{m}}{V} \frac{R T}{N_{A}} .
$$

where $k$ is the lateral thrust coefficient; $\gamma$ is the volume weight of rocks containing a coal rock; $H$ - the depth of the reservoir; $V$ - is the volume of the filtration space; $N_{m}$ - the number of gas molecules; $N_{A}$ - is the Avogadro number equal to $6 \cdot 10^{23} \mathrm{~mol}^{-1} ; R-$ is the universal gas constant; $T$ - rock temperature.

The value of $N_{m} / V$ on the right side of equation (7) is the concentration of methane in the filtration space of the coal rock. Having solved equation (7) with respect to this quantity, we will have:

$$
c_{R}=\frac{k \gamma H N_{A}}{R T} .
$$

As an example, a calculation was made of the change in the concentration of sorbed methane in a coal fragment at a depth of $1000 \mathrm{~m}$ when deformations in the mountain rock did not lead to a change in the molecular structure of coal, characterized by conformational rearrangements. Then you can use the numerical values of the diffusion coefficient which calculated in [3] and equal $D=8.4 \cdot 10^{-15} \mathrm{~m}^{2} / \mathrm{s}$. For the depth $1000 \mathrm{~m}$, where the temperature is, on average $308 \mathrm{~K}[6]$, and the volume weight rocks $13 \mathrm{~N} / \mathrm{m}^{3}$, as well as a $20 \%$ concentration of free gas in the rock, the numerical value of the constant $c_{R}$ will be $3 \cdot 10^{24} \mathrm{~m}^{-3}, c_{0}=12 \cdot 10^{24} \mathrm{~m}^{-3}$.

The results of the calculation are presented in Figure 1.

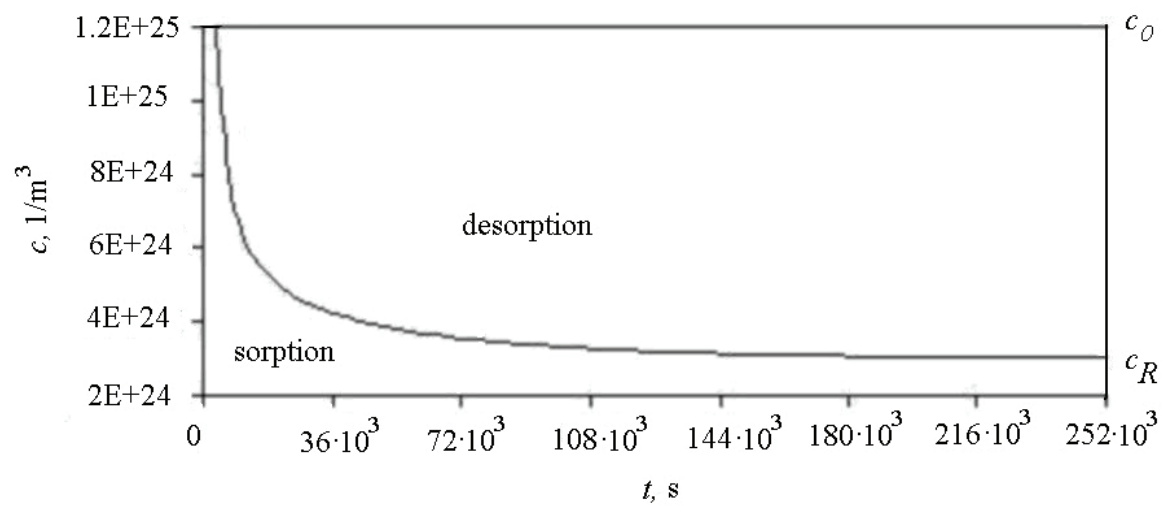

Fig 1. The concentration distribution of sorbed methane in time in the absence of conformational rearrangements in the microstructure of the coal fragment.

From Figure 1 can be seen that over time, the volume of released methane from the coal fragment increases as it desorbs exponentially. The most intense desorption occurs, approximately, for 8-10 hours. Further, the desorption intensity is reduced. And after 50 hours, the desorption process stops and the concentration of sorbed methane in the whole fragment is compared with the concentration of gas in the filtration space.

Thus, as a result of the research, the following conclusions were made. 


\section{Conclusions}

1. It has been established that the basis for modeling methane desorption in a coal rock is to consider it as an activated diffusion process in a high-polymer environment, taking into account that the sorption intermolecular interconnection in the "methane-coal" system can be described by Lennard-Jones potential.

2. A model of the desorption process of methane in a coal rock is represented by the diffusion equation (1) with a diffusion coefficient (2), which takes into account the diffusion activation energy (3), as well as the complex structural parameters of the molecular structure of coal, the physical properties of methane, the magnitude of its diffusion jump in a given molecular structure and Lennard-Jones potential parameters.

3. The analytical expression obtained by simulation for calculating the laws of the desorption process has the exponential form (5). Taking into account the boundary conditions obtained for the coal rock (6) and (8). This equation allows us to establish the desorption dependencies of methane in various geological conditions of coal production operations.

\section{References}

1. Aleksieiev, A., Synolytskyi, V. (1985). Kinetics of absorption and gas evolution by porous solids, Journal of Engineeering Physics and Thermophysics, 49 (4), 648 - 654

2. Minieiev, S. (2009). Properties of gas-saturated coal. Edited by S. Minieiev. Dnipropetrovsk: NSU

3. Minieiev, S.P. Prusova, A.A., Kornilov, M.G. (2007). On the activation energy of methane diffusion in a coal rock, Geotechnical mechanics, 69, 68-74

4. Lyakh, V., Mineev, S. (1994). Mathematical simulation of vibration action upon a gassaturated coal rock. Prikladnaya Matematika i Mekhanika

5. Bulat, A.F., Mineev, S.P., Prusova, A.A. (2016). Generating methane adsorption under relaxation of molecular structure of coal, Journal of Mining Science, 52 (1), 70-79

6. Minieiev, S., Rubinsky, O., Vitushko, O., Radchenko, O. (2010). Mining in difficult conditions on outburst coal rocks. Donetsk: Skhidnyy vidavnichy dim

7. Minieiev, S.P. (2016). Forecast and ways of dealing with gas-dynamic phenomena in the mines of Ukraine. Mariupol: Oriental Publishing House

8. Kuznetsov, S., Trofimov, V. (1999). The main task of gas filtration in coal rocks, Journal of Mining Science, 5, 13-18

9. Minieiev, S., Prusova, A., Kornilov, M. (2006). Dynamics of methane adsorption in coal micropores, Geotechnical mechanics, 67, 179-184

10. Saranchuk, V., Ayruni, A., Kovalev, K. (1988). Supramolecular organization, structure and properties of coal. Kyiv: Naukova Dumka

11. Sklyar, M., Soldatenko, E., Valters, N. (1985). On some features of the molecular and supramolecular structure of coal. Kyiv: Naukova Dumka

12. Krichko, A., Gagarin, S., Skripchenko, G. (1985). The nature of chemical bonds in coal and their reactivity. Kyiv: Naukova Dumka

13. Dubinin, M., (1983). Microporous structures of carbon adsorbents. Moskva: Nauka

14. Kuzmichev, V. (1989). The laws and formulas of physics. Kyiv: Naukova Dumka

15. Burkert, U., Ellinger, N. (1986). Molecular mechanics. Moskva: Mir

16. Bobin, V., Zimakov, V., Odintsev, V. (1989). Estimation of the energy of intermolecular repulsion of sorbate molecules in the micropores of coal. Journal of Mining Science, 5, 48-56

17. Klopffer, M.H., Flaconneche, B. (2001). Transport Properties of Polymers: Bibliographic Review, Oil \& Gas Science and Technology, 56 (3), 223-244 
18. George, S. C., Thomas, S. Prog. Polym. Sci. 26, 985-1017(2001)

19. Kiparissides, C., Dimos, V., Boultouka, T., Anastasiadis, A., Chasiotis, A. 87, 953-966 (2003)

20. Ganesh, K., Nagarajan, R., Duda, J.L. Ind. Eng. Chem. Res. 31 746-755 (1992)

21. Kalospiros, N.S., Ocone, R., Astarita, G., Meldon, J.H. Ind. Eng. Chem. Res. 30. 851$881(1991)$

22. Aramanovich, I., Levin, V. (1969). Equations of mathematical physics. Moskva: Nauka

23. Godunov, S. (1979). Equations of Mathematical Physics. Moskva: Nauka 